\title{
Nitric oxide (NO) radical inhibitory of Hedyotis philippinensis and its marker compound, Asperuloside
}

\author{
Emi Norzehan Mohamad Mahbob ${ }^{1 *}$, Rohaya Ahmad² and Syahida Ahmad ${ }^{3}$ \\ ${ }^{1}$ Faculty of Applied Sciences, Universiti Teknologi MARA (Perak) Kampus Tapah, 35400 Tapah Road, Tapah, Perak, Malaysia \\ ${ }^{2}$ Faculty of Applied Sciences, Universiti Teknologi MARA, 40450 Shah Alam, Selangor, Malaysia \\ ${ }^{3}$ Institute of Bioscience, Universiti Putra Malaysia, 43400, Serdang, Selangor, Malaysia \\ *Corresponding Author: emino593@perak.uitm.edu.my (E.N.M. Mahbob)
}

Article history :

Received 1 Januari 2013

Revised 24 May 2013

Accepted 6 July 2013

Available online 1 August 2013

\section{GRAPHICAL ABSTRACT}

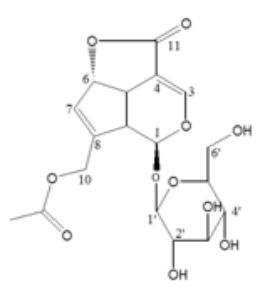

Asperuloside

\begin{abstract}
Hedyotis spesies have been used in Chinese folk medicine as a treatment for colds, stomatitis and various inflammations. In this study, three methanolic extracts of Hedyotis species (Hedyotis corymbosa, Hedyotis havilandii and Hedyotis philippinensis) were screened for their anti-inflammatory activity. The plant extracts along with asperuloside, the marker compound of $H$. philippinensis were tested for their antiinflammatory effect against lipopolysaccharide (LPS) and interferon- $\gamma$ (IFN- $\gamma$ )-induced nitric oxide (NO) production using RAW264.7 macrophage cells. Among the three species, H. philippinensis (leaves and stems) showed good NO radical inhibitory activity (with $\mathrm{IC}_{50}$ values of $139.76 \pm 12.50$ and $176.21 \pm 2.48$ $\mu \mathrm{g} / \mathrm{ml}$, respectively). Asperuloside, isolated as a major compound from the plant moderately inhibited LPS/IFN- $\gamma$-induced NO production by $63 \%$ at a concentration of $100 \mu \mathrm{M}$ ( $45 \%$ cell viability) compared to L-NAME (77 \%). Its $\mathrm{IC}_{50}$ value was found to be $75.45 \pm 2.25 \mu \mathrm{M}$. Its inhibition was also found to be dosedependent.
\end{abstract}

Keywords: Hedyotis philippinensis, Asperuloside, Anti-inflammatory, Nitric oxide, Lipopolysaccharide (LPS), Interferon- $\gamma(I F N-\gamma)$

(C) 2014 Penerbit UTM Press. All rights reserved http://dx.doi.org/10.11113/mjfas.v10n1.62

\section{INTRODUCTION}

Hedyotis species have been known to contain natural products of diverse structures including iridoids, flavonoids, anthraquinones and triterpenes. This genus is a well-known medicinal plant endogenous to China which has been used in ancient times and is still used as a treatment of cancer and inflammations such as appendicitis, urethritis and bronchitis [1].

Inflammation is a normal, robust physiological process. It can also be viewed as a complex system that senses and resolves homeostatic perturbations initiated from within the body (for example, in autoimmune disease) or from the outside (for example, in infections). Virtually, all acute and chronic diseases are either driven or modulated by inflammation [2]. The most pivotal enzymes involved in maintaining inflammation are the inducible enzymes; inducible nitric oxide synthase (iNOS/NOS2) and cyclooxygenase-2 (COX-2), which are responsible for the catalysis of $\mathrm{NO}$ and prostaglandin E2 (PGE2), respectively. During inflammatory disease, the macrophage produces excess amounts of mediators such as nitric oxide (NO), prostanoids and pro-inflammatory cytokines [3]. NO being a potent vasodilator is an important mediator since it leads to an increase in blood flow [4]. However, excess NO production has been implicated in septic shock and autoimmune diseases.

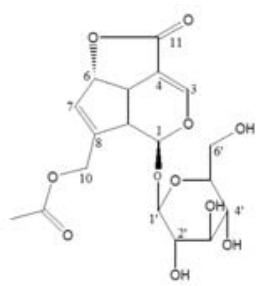

Fig. 1 Asperuloside

For this reason, inhibition of NO production has been identified as a promising therapy for the treatment for inflammatory diseases [5]. The search for inflammatory inhibitors from natural sources has been an alternative approach in development of anti-inflammatory drugs [6].

Previous pharmacological studies of Hedyotis species have shown that these species possessed antiinflammatory activities $[7,8]$. To date, three major classes of compound including iridoid glycosides, flavonoids, and 
anthraquinones have been reported as bioactive compounds from these group of herbs [9]. Asperuloside, an iridoid glycoside (Figure 1.0) has been reported as a potent antiinflammatory agent [10] along with other iridoid glycosides. Iridoids represent a large group of cyclopentanoid monoterpene derivatives and are found as natural constituents in a large number of plant families, usually as glucosides. They have shown various activities such as antimicrobial, antitumoral, hemodynamic, choleretic and hepatoprotective [11, 12, 13].Considering the importance of pharmacological properties of natural products derived from plants, three Hedyotis species (Hedyotis corymbosa, Hedyotis havilandii and Hedyotis philippinensis) have been selected for the evaluation of their anti-inflammatory property via NO-inhibition.

\section{EXPERIMENTAL}

\subsection{Materials, method and instruments}

RAW 264.7 cells were purchased from the European Collection of Cell Cultures (Porton Down, Salisbury, UK). Antibiotics (5000 U/ml penicillin and $5000 \mu \mathrm{g} / \mathrm{ml}$ streptomycin) and Dulbecco's Modified Eagle's Media (DMEM) were purchased from Flowlab ${ }^{\mathrm{TM}}$. Foetal bovine serum (FBS) was purchased from Gibco/BRL. Recombinant mouse IFN- $\gamma$ was purchased from BD Pharmingen, USA and lipopolysaccharide from E. coli strain Serotype 0111:B4 was purchased from Sigma-Aldrich (St. Louis, MO, USA). Sulfanilamide, naphtylethylenediamine dihydrochloride and phosphoric acid, which are composition of Griess reagent were purchased from Sigma-Aldrich (St. Louis, MO, USA) whilst the 3-(4,5-dimethylthiazol-2-yl)-2,5-diphenyl tetrazolium bromide (MTT), which was used in determining cell viability was purchased from Fluka, BioChemika, Buchs, Switzerland. UV spectra were recorded on Shimadzu UV-Vis 160 spectrophotometer. Infrared (IR) spectra were performed on Perkin Elmer 1600 FTIR spectrometer. ${ }^{1} \mathrm{H}$ - and ${ }^{13} \mathrm{C}$-NMR spectra were recorded on Avance Bruker 300 and $75 \mathrm{MHz}$, respectively. $\mathrm{CD}_{3} \mathrm{OD}$ was used as solvent. Chemical shifts are given in $\delta$ ppm.

\subsection{Plant materials}

Three Hedyotis species (Hedyotis corymbosa, Hedyotis havilandii and Hedyotis philippinensis) evaluated in this study were collected from various parts of Malaysia and the voucher specimens were deposited at the Institute of Bioscience (IBS) Herbarium unit of UPM.

\subsection{TLC analysis and detection}

Detection of iridoid glycosides, flavonoids, alkaloids and terpenes was achieved by using spray detection reagents on previous developed TLC plates.

\subsubsection{Detection of iridoid glycosides}

The presence of iridoid glycosides were detected by the presence of deep blue spots on the surface of TLC. The spots were visualized by spraying with a mixture of anisaldehyde $(0.5 \mathrm{ml}), \mathrm{HOAc}(10 \mathrm{ml}), \mathrm{MeOH}(85 \mathrm{ml})$ and $\mathrm{H}_{2} \mathrm{SO}_{4}(5 \mathrm{ml})$ followed by heating.

\subsubsection{Detection of flavonoids}

The presence of flavonoids in the samples, were detected by the appearance of fluorescent yellow coloration on the TLC sheets when viewed under UV light (365 nm). The spots were sought in a revelation test with $\mathrm{AlCl}_{3}$ solution.

\subsubsection{Detection of alkaloids}

For the identification of alkaloids, the TLC sheets were revealed by the reagent of Dragendorff. The appearance of orange spots on the surface of TLC certified the presence of alkaloids in the samples.

\subsubsection{Detection of terpenes}

For the identification of terpenes, the TLC sheets were revealed by spraying with vanillin-sulphuric acid test solution followed by heating on a hot plate. The appearance of red and blue spots on the surface of TLC certified the presence of terpenes in the samples.

\subsection{Isolation of asperuloside from Hedyotis philippinensis stems extract}

The ethanolic extracts of $H$. philippinensis stems were partitioned via solid phase extraction (SPE) into four main fractions; $\mathrm{ES}_{1}, \mathrm{ES}_{2}, \mathrm{ES}_{3}$ and $\mathrm{ES}_{4}$, using a gradient $\mathrm{H}_{2} \mathrm{O}-\mathrm{MeOH}$ as a solvent system. A portion of the fraction $\mathrm{ES}_{2}(8 \mathrm{~g})$ was dissolved in $\mathrm{MeOH}$ and was fractioned on reverse phase silica gel (Merck 10167) medium pressure liquid chromatography (MPLC) using a gradient $\mathrm{H}_{2} \mathrm{O}$ $\mathrm{MeOH}$ as a solvent system to yield 45 fractions. According to the TLC profile, the collected fractions were pooled to give six major fractions (labeled $\mathrm{SE}_{1}, \mathrm{SE}_{2}, \mathrm{SE}_{3}, \mathrm{SE}_{4}, \mathrm{SE}_{5}$ and $\mathrm{SE}_{6}$ ).

Fraction $\mathrm{SE}_{2}(994 \mathrm{mg})$ was rechromatographed on silica gel $\mathrm{CC}$ using successfully Hexane- $\mathrm{CH}_{2} \mathrm{Cl}_{2}$ (50:50, $\mathrm{v} / \mathrm{v}), \mathrm{CH}_{2} \mathrm{Cl}_{2}$ and a gradient $\mathrm{MeOH}-\mathrm{CH}_{2} \mathrm{Cl}_{2}$ as solvent systems to yield 80 fractions. Upon drying, fraction 32 yielded an amorphous white solid, asperuloside. Fractions 31-34 from fraction $\mathrm{SE}_{2}$ which were eluted via $\mathrm{MeOH}-$ $\mathrm{CH}_{2} \mathrm{Cl}_{2}(15: 85, \mathrm{v} / \mathrm{v})$ were further purified using preparative TLC (silica gel $60 \mathrm{~F}_{254} 1 \mathrm{~mm}$, Merck, $20 \mathrm{~cm}$ x $20 \mathrm{~cm}$ ) with multiple development (three times) in the solvent system of $\mathrm{MeOH}-\mathrm{CH}_{2} \mathrm{Cl}_{2}(10: 90, \mathrm{v} / \mathrm{v})$. The identified band was scrapped and the compound was then recovered by washing with a mixture of $\mathrm{CH}_{2} \mathrm{Cl}_{2}-\mathrm{MeOH}(50: 50, \mathrm{v} / \mathrm{v})$ to afford asperuloside. 
Asperuloside, white powder, UV $(\mathrm{MeOH}) \lambda_{\max } 235$ nm, IR (KBr) $v_{\max } 3401(\mathrm{OH}), 1736(\mathrm{C}=\mathrm{O}), 1660(\mathrm{C}=\mathrm{C})$, 1267 (C-O) $\mathrm{cm}^{-1}$, Positive ion ESIMS m/z $415[\mathrm{M}+\mathrm{H}]^{+}$, $437[\mathrm{M}+\mathrm{Na}]^{+}$(calc. for $\mathrm{C}_{18} \mathrm{H}_{22} \mathrm{O}_{11}$ ), ${ }^{1} \mathrm{H}-\mathrm{NMR}(300 \mathrm{MHz}$, $\left.\mathrm{CD}_{3} \mathrm{OD}\right) \delta: 7.30(1 \mathrm{H}, \mathrm{d}, J=1.8 \mathrm{~Hz}, \mathrm{H}-3), 5.98(1 \mathrm{H}, \mathrm{s}, \mathrm{H}-1)$, $5.75(1 \mathrm{H}, \mathrm{s}, \mathrm{H}-7), 5.60(1 \mathrm{H}, \mathrm{d}, J=6.3 \mathrm{~Hz}, \mathrm{H}-6), 4.68(2 \mathrm{H}, \mathrm{d}$, $J=14.4 \mathrm{~Hz}, \mathrm{H}-10), 3.70$ (1H, dd, $J=12.0 / 2.4 \mathrm{~Hz}, \mathrm{H}-5), 3.32$ $(1 \mathrm{H}, \mathrm{q}, J=3.3 \mathrm{~Hz}, \mathrm{H}-9), 2.09\left(3 \mathrm{H}, \mathrm{s}, \mathrm{CH}_{3}\right), 4.60-3.23$ (sugar $\mathrm{H})$.

\section{$2.5 \quad$ Nitric oxide inhibitory activity}

\subsubsection{Cell culture}

The RAW 264.7 cells were grown in plastic culture flasks in Dulbecco's Modified Eagle's Medium (DMEM) with phenol red containing HEPES, L-glutamine supplemented with $10 \%$ foetal bovine serum (FBS) and $1 \%$ antibiotic/antimycotic solution under $5 \% \mathrm{CO}_{2}$ at $37{ }^{\circ} \mathrm{C}$. After 4-5 days, the cells were removed from the culture flask by scraping and were then centrifuged for $10 \mathrm{~min}$ at $3000 \mathrm{rpm}$ and at $4{ }^{\circ} \mathrm{C}$. The medium was then removed and the cells were suspended with fresh DMEM without phenol red containing HEPES and L-glutamine with the same supplements. Cell counts and viability were measured using a standard trypan blue cell counting technique. The cell concentration was adjusted to $1 \times 10^{6}$ cells $/ \mathrm{ml}$ in the same medium. Apart from the normal cell controls, all cells were cultured in the above media $(50 \mu \lambda)$, which also contained inducing agents such as $200 \mathrm{U} / \mathrm{ml}$ of recombinant murine IFN- $\gamma$ and $10 \mu \mathrm{g} / \mathrm{ml}$ lipopolysacharide (LPS) seeded into the wells of 96-well tissue culture plates. Then, $50 \mu 1$ of serially diluted plant extracts in media containing DMSO were dispensed into the wells of the cell plates to yield a final concentration of DMSO at $0.1 \%$ per wall. Extracts were used in triplicates and the cells were incubated for $24 \mathrm{~h}$ at $37{ }^{\circ} \mathrm{C}, 5 \% \mathrm{CO}_{2}$, in a fully humidified incubator.

\subsubsection{Measurement of nitrite}

To determine the nitric oxide concentration, the stable nitric oxide conversion product, nitrite $\left(\mathrm{NO}_{2}{ }^{-}\right)$was measured using the Griess reagent. After $24 \mathrm{~h}$ of incubation, $50 \quad 1$ aliquots were removed from supernatants of cultured cells and incubated with equal volume of the Griess reagent (1\% sulfanilamide, $0.1 \% \mathrm{~N}$-(1-naphthyl)ethylene diamine dihydrochloride, $2.5 \% \mathrm{H}_{3} \mathrm{PO}_{4}$ ) at room temperature for $10 \mathrm{~min}$. The absorbance at $550 \mathrm{~nm}$ was determined in a microplate reader (SpectraMax, Plus 384, Molecular Devices, Inc., USA). The concentrations of nitrite were derived by regression analysis using serial dilutions of sodium nitrite as a standard. Percentage inhibition was calculated, based on the ability of extracts to inhibit nitrite below the levels produced by cells cultured in the presence of triggering agents and DMSO, which was considered as $0 \%$ inhibition.

\subsubsection{Measurement of cell viability}

To determine that the observed nitric oxide inhibition was not false positive due to cytotoxic effects, a cytotoxicity assay was also performed following culture. After removal of media, the cells were topped up with 100 $\mu \lambda$ of complete DMEM. To each well, $20 \mu \lambda$ of a solution of $5 \mathrm{mg} / \mathrm{ml}$ of 3-(4,5-dimethyl-thiazol-2-yl)-2,5diphenyltetra-zoliumbromide (MTT) in PBS 7.2 were added. The cells were incubated at $37{ }^{\circ} \mathrm{C}$ with $5 \% \mathrm{CO}_{2}$ for $4 \mathrm{~h}$. The medium was then carefully discarded and the formazan salt formed was dissolved in DMSO. The absorbance was read at $570 \mathrm{~nm}$. The absorbance of formazan in control (untreated cells) was taken as 100\% viability.

\subsection{Statistical analysis}

All experiments were performed in triplicates. Means and standard deviations were calculated from replicates in the experiments and analyses using Microsoft Excel XP and SPSS 14.0 software. Significance analysis was performed by ANOVA $(P<0.05)$.

\section{RESULTS \& DISCUSSION}

\subsection{Screening of phytochemicals by thin layer chromatography}

In this study, a qualitative phytochemical screening was initially performed on the crude methanolic extracts of three Hedyotis species for the presence of metabolites that are potentially bioactive such as alkaloids, flavonoids, iridoids and terpenoids [7, 14]. The phytochemical profiles of the plants summarized in Table 1.0 indicated the presence of iridoids and terpenoids in all the extracts and the presence of alkaloids only in $H$. corymbosa. Interestingly, all tested samples showed the presence of flavonoids in all samples except for $H$. corymbosa. Studies have shown that the presence of bioactive metabolites such as flavonoids may contribute to the anti-inflammatory properties of plant extracts [15].

Table 1 Phytochemical screening on extracts of three Hedyotis species by TLC

\begin{tabular}{llcccc}
\hline Genus & Species & Alkaloid & Flavonoid & Iridoid & Terpenoid \\
\hline Hedyotis & H. corymbosa & + & - & + & + \\
& H. havilandii & - & + & + & + \\
& $\begin{array}{l}\text { H. philippinensis } \\
\text { (leaves) }\end{array}$ & - & + & + & + \\
& $\begin{array}{l}\text { H. philippinensis } \\
\text { (stems) }\end{array}$ & - & + & + & + \\
+: Presence of constituent & -: Absence of constituent & &
\end{tabular}

\subsection{Inhibition effect of asperuloside and three Hedyotis species on NO production}

Macrophages play a central role in the overproduction of pro-inflammatory cytokines and inflammatory mediators such as NO [16]. Thus, in vitro 
anti-inflammatory properties of plant extracts have been investigated in the search of new NO inhibitors from medicinal plants with the aim of developing new herbal formulation to treat inflammation. Total NO production was evaluated by measuring the accumulation of nitrite $\left(\mathrm{NO}_{2}{ }^{-}\right)$in the culture supernatant using the Griess reagent where quantitation of NO was based on a calibration curve prepared by using sodium nitrite as a standard.

In this study, the extracts were tested at seven different dose levels to investigate whether their inhibitory actions toward NO formation were dose-dependent. The inhibitory effect on lipopolysaccharide (LPS) and interferon- $\gamma($ IFN- $\gamma$ )-induced nitric oxide (NO) production was shown by the extracts of $H$. philippinensis leaves with an $\mathrm{IC}_{50}$ value of $139.76 \pm 12.50 \mu \mathrm{g} / \mathrm{ml}$ followed by $H$. philippinensis stems $(176.21 \pm 2.48 \mu \mathrm{g} / \mathrm{ml})$. As indicated by their cell viability values (Table 2.0 ), the inhibition was not due to their cytotoxicity.

Our previous anti-inflammatory study on other Hedyotis species has found that Hedyotis nudicaulis (aerial parts), Hedyotis verticillata (leaves) and Hedyotis capitellata (stems) were found to exhibit moderate inhibition on NO production (about $40 \%$ ) at the highest concentration of $100 \mu \mathrm{g} / \mathrm{ml}$. It seemed that the activity shown was in a dose-dependent manner [7]. Moreover, in another study done by Saha et al. [8], $H$. verticillata showed strong inhibitory activity on nitric oxide production in induced cells $(84.89 \%$ at a concentration of $250 \mathrm{~g} / \mathrm{ml})$ and the results were supported by the cell viability experiment (cell viability $>90 \%$ ).

Table 2 Inhibitory effects of plant extracts on LPS-stimulated NO released from RAW264.7 cells

\begin{tabular}{lccc}
\hline Sample & $\begin{array}{c}\mathrm{IC}_{50} \text { value } \\
(\mu \mathrm{g} / \mathrm{ml})\end{array}$ & $\begin{array}{c}\text { Percentage } \\
\text { inhibition }^{\mathrm{a}}\end{array}$ & $\begin{array}{c}\text { Percentage cell } \\
\text { viability }^{\mathrm{a}}\end{array}$ \\
\hline H. corymbosa & $\mathrm{Na}$ & $28.54 \pm 9.50$ & $14.22 \pm 0.13$ \\
H. havilandii & $\mathrm{Na}$ & $40.86 \pm 3.94$ & $47.81 \pm 4.11$ \\
H. philippinensis $(\mathrm{L})$ & $139.76 \pm 12.50$ & $65.29 \pm 5.49$ & $80.47 \pm 12.85$ \\
H. philippinensis $(\mathrm{S})$ & $76.21 \pm 2.48$ & $53.88 \pm 5.58$ & $78.29 \pm 11.44$ \\
\hline
\end{tabular}

\begin{tabular}{cccc} 
H. philippinensis $(\mathrm{S})$ & $76.21 \pm 2.48$ & $53.88 \pm 5.58$ & $78.29 \pm 11.44$ \\
\hline $\mathrm{Na}=$ activity more than 250 & $\mu \mathrm{g} / \mathrm{ml}$. The values shown are means $\pm \mathrm{SD}$ of three
\end{tabular} experiments (three cultures per experiment). The values differ significantly at a level of $P<0.05$. Significance analysis was performed by ANOVA. ${ }^{\text {a }}$ Values expressed at a concentration of $250 \mu \mathrm{g} / \mathrm{ml}$.

The determination of phytochemicals is an important task in justifying the rationale for the use of the plants in traditional medicine. Therefore, phytochemical screening by TLC can be utilised as a broad-spectrum screening for the preliminary identification of compounds present. However, the TLC results are only qualitative and cannot be quantified. The formation of blue colour on TLC spot upon heating after application of anisaldehyde reagent indicated the presence of iridoid. The blue colour on the TLC will also appear if the compounds react positively with vanillin-sulphuric acid solution, indicating the presence of terpenoids. For alkaloids detection, a positive result is indicated by an orange or red spot appearing after spraying with the Dragendorff's reagent. The presence of flavonoids in the tested samples can be characterized by the presence of yellow coloration in a test with $\mathrm{AlCl}_{3}$ solution.
The yellow fluorescence colour is visible under UV light at $365 \mathrm{~nm}$. Interestingly, the results of phytochemical screening (Table 1.0) supported the role of the phytochemicals in the observed inhibitory effects shown in Table 2.0.

On the basis of its $\mathrm{IC}_{50}$ value, $H$. philippinensis has been chosen for further phytochemical investigation. The phytochemical investigation of $H$. philippinensis has led to isolation of asperuloside as a major compound. Asperuloside, an iridoid derivative has attracted a special interest. Studies have shown this compound possess antiinflammatory activity. A study in treating rheumatoid arthritis done by Li et al. [10] has found that the compound exhibited an inhibitory effect on the release of TNF- $\alpha$ from cultured mouse peritoneal macrophages with $\mathrm{IC}_{50}$ values of $0.52 \mu \mathrm{g} / \mathrm{ml}$. TNF- $\alpha$ is a proinflammatory cytokine tumor necrosis factor- $\alpha$ which regulates systemic responses to microbial infection or tissue injury. Suppression of TNF- $\alpha$ is crucial for inflammatory diseases management since reduction of TNF- $\alpha$ genes expression might be due to inhibition of NF- $\mathrm{BB}$ nuclear translocation [15], as NF- $\kappa \mathrm{B}$ induces the transcription of inflammatory cytokines and COX-2 [14].

In a recent study, Zhu et al. [17] reported that asperuloside together with two other iridoid glycosides paederoside and scanderoside exert a protective effect against renal injury in uric acid nephropathy (UAN) rats and possess anti-inflammatory and immunomodulatory

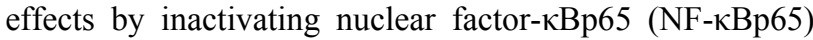
pathway transmembrane signal transduction, down regulating the expression of monocyte chemoattractant protein-1 (MCP-1) and $\alpha$-smooth muscle actin ( $\alpha$-SMA) to modulate pro-inflammatory mediator production in nephropathy tissue to improve renal fibrosis in UAN rats. In another recent study by Liu et al. [18], iridoid glycosides of Paederia scandens (IGPS) including asperuloside was found to possess antinociceptive effect against peripheral nerve injury in a rat model of neuropathic pain. Inhibition of $\mathrm{NO} /$ cyclic guanosine monophosphate (cGMP)/protein kinase gene (PKG) pathway might be partly involved in the mechanism by which IGPS is effective as an analgesic therapeutic agent. Furthermore, IGPS was found to potently down-regulate spared nerve injury (SNI)-induced NO production by inhibiting iNOS expression at the gene level. It is likely that IGPS could be developed as a powerful approach to prevent elevation of NO by inhibition of iNOS expression, and alleviate pain state in response to peripheral nerve injury in SNI model.

In this study, asperuloside was examined for its inhibitory effect on $\mathrm{NO}$ enhanced production from LPS/IFN- $\gamma$-stimulated macrophages (one of the inflammatory mediators). LPS/IFN- $\gamma$-stimulated macrophage cells with or without treatment with the asperuloside, were incubated for $24 \mathrm{~h}$, and then NO levels were determined. The results indicated that at $100 \mu \mathrm{M}$, asperuloside inhibited NO production with $62.96 \pm 0.43 \%$ inhibition (Table 3.0) while L-NAME (a standard NOS 
inhibitor) used as a positive control caused a significant inhibition of $76.67 \pm 3.81 \%$ at the same concentration. The $\mathrm{IC}_{50}$ value of asperuloside was calculated to be $75.45 \pm 2.25$ $\mu \mathrm{M}$.

To identify the cytotoxic effect of plant extracts, its effects on the viability of a RAW 264.7 was evaluated using methylthiazol tetrazolium (MTT) assay to avoid false positives due to cytotoxic effects. The siginificant $(P<0.05)$ inhibition of nitrite production by these plant extracts (at different concentrations) was unlikely due to their toxicity, as suggested from the cell viability experiment (Table 2.0) with the exception of $H$. corymbosa. This indicates that this extract may possess anti-cancer property, as is evident for $H$. corymbosa which is used as an ingredient in herbal formulations for anti-cancer [19].

A compound is considered to be cytotoxic when the optical density of the sample-treated group was less than $80 \%$ of that in the control group [6]. For asperuloside, the cell viability was strongly affected at the highest concentration of $100 \mu \mathrm{M}$ with cell survival of $44.95 \pm 6.30 \%$. However, the toxicity effects of the compound to the cells treated decreased at lower concentrations. Due to the cytotoxicity effect showed by asperuloside, it can be similarly suggested that this compound may possess anti-cancer properties. However to date, there has been no report on the anti-cancer properties of the compound.

Table 3 Percent inhibition of nitric oxide accumulation in cell culture supernatants of macrophages by asperuloside

\begin{tabular}{lccc}
\hline Sample & $\begin{array}{c}\text { Concentration } \\
(\mu \mathrm{M})\end{array}$ & $\begin{array}{c}\text { Percentage } \\
\text { inhibition }\end{array}$ & $\begin{array}{c}\text { Percentage cell } \\
\text { viability }\end{array}$ \\
\hline Asperuloside & 100 & $62.96 \pm 0.43$ & $44.95 \pm 6.30$ \\
& 50 & $36.47 \pm 1.98$ & $73.53 \pm 6.95$ \\
25 & $33.74 \pm 6.71$ & $72.25 \pm 3.47$ \\
& 12.5 & $35.12 \pm 4.88$ & $82.71 \pm 9.18$ \\
6.25 & $25.19 \pm 4.15$ & $87.05 \pm 7.39$ \\
& 3.13 & $18.77 \pm 3.16$ & $87.44 \pm 8.21$ \\
& 1.56 & $18.46 \pm 2.44$ & $93.00 \pm 4.32$ \\
\hline The values shown are means \pm SD of three experiments (three cultures per experiment). The values
\end{tabular}

differ significantly at a level of $P<0.05$. Significance analysis was performed by ANOVA.

The absence of cytotoxic effects of the plants extracts tested was not surprising since most of these plants have been used in herbal formulation as ingredients in the form of decoction or in traditional medicines. The plants exhibiting inhibitory activity on NO production can be promising candidates for the isolation of active component in which they may have potential for the treatment of inflammation due to the overproduction of NO.

\section{CONCLUSION}

In this study, we have found that $H$. philippinensis possessed an $\mathrm{IC}_{50}$ value of $139.76 \pm 12.50 \mathrm{~g} / \mathrm{ml}$ in the Griess assay for NO inhibition which could justify the use of the plant for inflammation. Moreover, the absence of cytotoxicity in all extracts tested could justify the ethnomedical use of the plant. Phytochemical investigation on the stems and leaves of $H$. philippinensis successfully yielded the major compound asperuloside (iridoid glycoside), astragalin (flavonoid glycoside), and scopoletin (coumarin). The major compound asperuloside moderately inhibited LPS/IFN- -induced NO production by $63 \%$ with $45 \%$ cell viability at a concentration of $100 \mathrm{M}$ in a dosedependent manner. The in vitro inhibition of inflammatory mediator NO by the major compound asperuloside may account for the anti-inflammatory activity of $H$. philippinensis. However, further anti-inflammatory bioassays should be conducted on the compound to confirm its activity and its mode of action.

\section{ACKNOWLEDGEMENT}

The authors would like to thank the Research and Management Institute (RMI), Universiti Teknologi MARA, for research grant 600-RMI/ST/FRGS 5/3/FST(35/2009). Appreciation also goes to Dr Shamsul Khamis from Universiti Putra Malaysia for collection and identification of plants

\section{REFERENCES}

[1] J-N. Peng, X-Z. Feng, and X-T. Liang, Phytochemistry, 47 (1998) 1657-1659.

[2] Y. Vodovots, G. Constantine, J. Rubin, M. Csete, E. O. Voit, and G. An, Mathematical Biosciences, 217 (2009) 1-10.

[3] D. A. Israf, T. A. Khaizurin, A. Syahida, N. H. Lajis, and S. Khozirah, Molecular Immunology, 44 (2007) 673-679.

[4] A. Panossian, and G. Wikman, Journal of Ethnopharmacology, 118 (2008) 183-212.

[5] Q-Y. Lin, L-J. Jin, Z-H. Cao, H-Q. Li, and Y-P. Xu, Journal of Ethnopharmacology, 118 (2008) 495-502.

[6] S. Tewtrakul, C. Wattanapiromsakul, and W. Mahabusarakam, Journal of Ethnopharmacology, 121 (2009) 379-382.

[7] R. Ahmad, A. M. Ali, D. A. Israf, N. H. Ismail, K. Shaari, and N. H. Lajis, Life Sciences, 76 (2005) 1953-1964.

[8] K. Saha, N. H. Lajis, D. A. Israf, A. S. Hamzah, S. Khozirah, S. Khamis, and A. Syahida, Journal of Ethnopharmacology, 92 (2004) 263-267.

[9] C. Li., X. Xue, D. Zhou, F. Zhang, Q. Xu, L. Ren, and X. Liang, Journal of Pharmaceutical and Biomedical Analysis, 48 (2008) 205-211.

[10] B. Li, D-M. Zhang, Y-M. Luo, and X-G. Chen, Chemical \& Pharmaceutical Bulletin, 54 (2006) 297-300.

[11] S-K. Ling, T. Tanaka, and I. Kouno, Biological \& Pharmaceutical Bulletin, 26 (2002) 352-356.

[12] K. Chervenkova, and B. Nikolova-Damyanova, Journal of Liquid Chromatography and Related Technologies, 23 (2000) 741-753.

[13] M. D. C. Recio, R. M. Giner, S. Manez, and J. L. Rios, Planta Medica, 60 (1994) 232-234.

[14] F. Abas, N. H. Lajis, D. A. Israf, S. Khozirah, and Y. Umi Kalsom, Food Chemistry, 95 (2006) 566-573.

[15] S. Ahmad, D. A. Israf, N. H. Lajis, K. Shaari, H. Mohamed, A. A. Wahab, K. T. Ariffin, W. Y. Hoo, N. A. Aziz, A. A. Kadir, M. R. Sulaiman, and M. N. Somchit, European Journal of Pharmacology, 538 (2006) 188-194.

[16] K. S. Kim, H. I. Rhee, E. K. Park, K. Jung, H. J. Jeon, J-H. Kim, H. Yoo, C-K. Han, Y-B. Cho, C. J. Ryu, H. I. Yang, M.C. Yoo, Chinese Medicine, 3 (2008) 3-10.

[17] W. Zhu, M. Pang, L. Dong, X. Huang, S. Wang, and L. Zhou, Life Sciences, 91 (2012) 369-376.

[18] M. Liu, L. Zhou, and C. Hu, Pharmacology, Biochemistry and Behavior, 102 (2012) 465-470.

[19] N. H. Lajis, and R. Ahmad, Studies in Natural Product Chemistry, Bioactive Natural Products (Part M), 33 (2006) 1057-1090. 